\title{
Selenite-induced cell death in Saccharomyces cerevisiae: protective role of glutaredoxins
}

\author{
Alicia Izquierdo, Celia Casas and Enrique Herrero \\ Departament de Ciències Mèdiques Bàsiques, IRBLleida, Universitat de Lleida, Montserrat Roig 2 , \\ 25008-Lleida, Spain
}

Correspondence

Enrique Herrero

enric.herrero@cmb.udl.cat

Received 12 March 2010

Revised 11 May 2010

Accepted 28 May 2010

\begin{abstract}
Unlike in higher organisms, selenium is not essential for growth in Saccharomyces cerevisiae. In this species, it causes toxic effects at high concentrations. In the present study, we show that when supplied as selenite to yeast cultures growing under fermentative metabolism, its effects can be dissected into two death phases. From the time of initial treatment, it causes loss of membrane integrity and genotoxicity. Both effects occur at higher levels in mutants lacking Grx1p and Grx $2 p$ than in wild-type cells, and are reversed by expression of a cytosolic version of the membrane-associated Grx7p glutaredoxin. Grx7p can also rescue the high levels of protein carbonylation damage that occur in selenite-treated cultures of the grx 1 grx 2 mutant. After longer incubation times, selenite causes abnormal nuclear morphology and the appearance of TUNELpositive cells, which are considered apoptotic markers in yeast cells. This effect is independent of Grx1p and Grx2p. Therefore, the protective role of the two glutaredoxins is restricted to the initial stages of selenite treatment. Lack of Yca1p metacaspase or of a functional mitochondrial electron transport chain only moderately diminishes apoptotic-like death by selenite. In contrast, seleniteinduced apoptosis is dependent on the apoptosis-inducing factor Aif1p. In the absence of the latter, intracellular protein carbonylation is reduced after prolonged selenite treatment, supporting the supposition that part of the oxidative damage is contributed by apoptotic cells.
\end{abstract}

\section{INTRODUCTION}

Selenium (Se) is a trace element which may have anticarcinogenic action at low concentrations (Letavayová et al., 2006). The essential character of Se in the mammalian diet is related to its presence as selenocysteine in a number of selenoproteins, such as thioredoxin reductases and glutathione peroxidases (Lu \& Holmgren, 2009). These enzymes act in the defence against oxidative stress. In contrast, at high concentrations, Se is toxic because it generates oxidative stress and provokes DNA damage (Hatfield et al., 2006; Letavayová et al., 2006). Among the Se compounds that may come into contact with cells, selenite is a prooxidant because it undergoes glutathionemediated reduction to hydrogen selenide with the subsequent formation of superoxide radicals, which can undergo conversion into other reactive oxygen species (ROS) (Chen et al., 2007; Spallholz, 1997; Tarze et al., 2007). Saccharomyces cerevisiae is a suitable organism to study the toxic properties of Se and the cellular mechanisms which prevent or repair its effects, without the interference due to an Se requirement for selenoproteins. In fact, $S$. cerevisiae, and fungi in general, do not contain

Abbreviations: AlF, apoptosis-inducing factor; DAPI, 4,8-diamidino-2phenylindole; DNPH, dinitrophenylhydrazine; GRX, glutaredoxin; ROS, reactive oxygen species; TUNEL, terminal deoxynucleotidyl transferase dUTP nick end labelling. selenoproteins and therefore Se is not essential for these organisms (Lu \& Holmgren, 2009). High concentrations of Se cause DNA double-strand breaks in exponentially growing S. cerevisiae cells (Letavayová et al., 2008) and RAD9-dependent cell cycle arrest (Pinson et al., 2000). Accordingly, yeast mutants defective in the RAD9mediated DNA repair pathway or the RAD6/RAD18mediated DNA damage tolerance pathway are hypersensitive to sodium selenite (Seitomer et al., 2008), pointing to the importance of DNA damage in explaining Se toxicity to yeast cells. Analyses of mutants have also demonstrated the importance of the base excision repair pathway in tolerance to selenite (Mániková et al., 2010).

Transcriptome analysis of selenite-treated S. cerevisiae cells reveals overlapping of the Se and oxidative stress responses, by the common upregulation of genes for oxidoreductases and for proteasome protein components (Salin et al., 2008). This suggests that Se also causes damage to proteins. Yeast cells react to oxidative stress by synthesizing enzymes for ROS detoxification and for repairing macromolecular oxidative damage (Herrero et al., 2008). Glutaredoxins (GRXs) are thiol oxidoreductases that regulate the redox state of cysteine thiol groups (a main target of protein oxidants) by using GSH as reductant (Lillig et al., 2008). S. cerevisiae contains eight GRXs (Grxlp to Grx8p), which are in different cell compartments. The dithiol GRXs Grxlp 
and Grx2p (CPYC active site) are mainly cytosolic, but a minor portion of Grx2p is located within mitochondria (Luikenhuis et al., 1998; Porras et al., 2006). Despite the proposed role of Grxlp and Grx2p as general thiol oxidoreductases, their absence causes only moderate hypersensitivity to superoxide (in the case of Grxlp) and to superoxide and hydroperoxide (in the case of Grx2p) (Eckers et al., 2009; Luikenhuis et al., 1998). This phenotype could be explained based on the activity of these GRXs as glutathione peroxidases in in vitro assays (Collinson et al., 2002). Surprisingly, a grx2 mutant displays higher survival rates than wild-type cells in the presence of cadmium, which indirectly causes oxidative stress through deprivation of GSH (Gomes et al., 2008). Grx3p, Grx4p and Grx5p are monothiol GRXs (CGFS active site) and may have specialized functions related to iron homeostasis and iron-sulphur cluster synthesis in mitochondria (Herrero \& de la Torre-Ruiz, 2007; Pujol-Carrión et al., 2006; Rodríguez-Manzaneque et al., 1999). Grx6p and Grx7p are associated to membranes of the early secretory pathway, although their function is unknown (Izquierdo et al., 2008; Mesecke et al., 2008a, b). They have a singlecysteine active site, but their amino acid sequences are more similar to dithiol GRXs. Finally, Grx8p is a cytoplasmic dithiol enzyme with a non-standard CPDC active site and low activity in vitro (Eckers et al., 2009). Its absence does not cause significant growth phenotypes.

After application of diverse cellular stresses, S. cerevisiae cells may undergo apoptosis-like death (Madeo et al., 1999, 2004). Oxidative stress is among the apoptosis inducers in yeast (Perrone et al., 2008). Thus, hydrogen peroxide at low concentrations provokes apoptosis in a process dependent on the metacaspase Ycalp and on a functional mitochondrial respiratory chain, while high peroxide concentrations provoke non-apoptotic death (Khan et al., 2005; Madeo et al., 1999, 2002). Several metals and metalloids also cause apoptosis in yeast cells, which is probably related to their role in ROS formation. Thus, copper induces ROS-mediated apoptosis dependent on functional mitochondria, but not on Ycalp (Liang \& Zhou, 2007). Manganese is also an inducer of mitochondriondependent apoptosis, but contrary to copper, apoptotic death by manganese depends on Ycalp and does not correlate with intracellular ROS accumulation (Liang \& Zhou, 2007). Low cadmium concentrations induce Ycalpdependent apoptosis in S. cerevisiae, probably as a consequence of intracellular GSH depletion and redox imbalance (Gomes et al., 2008; Nargund et al., 2008). Arsenite also causes glutathione depletion and Yca1- and mitochondriondependent apoptosis in yeast cells (Du et al., 2007). These observations corroborate the existence of multiple pathways leading to apoptosis in yeast cells. On the other hand, a number of yeast cell treatments lead to non-apoptotic death (sometimes referred to as necrotic death), characterized by loss of plasma membrane integrity and consequent permeability to agents such as methylene blue and propidium iodide (Dudgeon et al., 2008; Madeo et al., 1999).
Recently, it has been reported that an S. cerevisiae mutant lacking Grx1p and Grx2p shows increased growth sensitivity to selenite (Lewinska \& Bartosz, 2008). This opened the possibility to study the relationship between GRXs and protection against Se toxicity. In this study, we demonstrate that selenite causes both non-apoptotic and apoptotic death, and that Grx1p and Grx2p protect against non-apoptotic death but not against apoptotic death. We also characterize Se-induced apoptosis, and employ the sensitivity phenotype of the grx 1 grx 2 mutant to study how other yeast GRXs are able to replace Grxlp and Grx $2 p$ functions in relation to protection against $\mathrm{Se}$ toxicity.

\section{METHODS}

Strains, plasmids and growth conditions. The $S$. cerevisiae strains used in this work are listed in Table 1. Except when indicated, they are derived from wild-type strain W303-1A (MATa ade2-1 his3-1 leu23,112 trp1-1 ura3-1 can1-100). Knockout strains had the respective ORF substituted by the indicated genetic marker, and were obtained by standard procedures (Wach et al., 1994) or after successive backcrosses of the mutants with the wild-type strain.

Plasmids pMM902 and pMM903 contain the respective coding sequences of GRX7 and GRX6 from codon 44 fused to an initial methionine codon, under the control of a tet $\mathrm{O}_{7}$ promoter in the URA3 vector pMM110. This is an integrative vector similar to other doxycycline-regulated expression plasmids described in Garí et al. (1997), obtained by moving an EcoRI-HindIII fragment with the tTA transactivator plus the tet $_{7}$ promoter and the $A D H 1$ terminator from pCM190, into the YIplac211 vector (Gietz \& Sugino, 1988). pMM960 derives from pMM902 by introducing a Cys to Ser substitution in the CPYS active site sequence of the GRX7 ORF, using the ExSite method for creating point mutations (Weiner \& Costa, 1995). Introduction of the desired mutation was confirmed by DNA sequencing. Integrative plasmid pMM950 contains the GRX1 ORF plus its own promoter and terminator sequences (783 and 357 bp, respectively), cloned in YIplac211. Plasmid pMM952 derives from pMM98 (Rodríguez-Manzaneque et al., 2002) by moving a PstIBamHI region which expresses a cytosolic form of Grx5p into YIplac211. Constructions were checked by DNA sequencing. Plasmids were chromosomally integrated at the URA3 locus after linearization by EcoRV digestion.

Cells were usually grown at $30{ }^{\circ} \mathrm{C}$ in YPD medium $[1 \%(\mathrm{w} / \mathrm{v})$ yeast extract, $2 \%(\mathrm{w} / \mathrm{v})$ peptone, $2 \%(\mathrm{w} / \mathrm{v})$ glucose]. Liquid cultures that had been growing exponentially for at least 10 generations were employed before sodium selenite (Sigma) addition. This was generally added at $6 \mathrm{mM}$ concentration. Both untreated and treated cultures were always maintained at concentrations lower than $4 \times 10^{7}$ cells $\mathrm{ml}^{-1}$ (equivalent to exponential growth conditions in untreated cultures), to avoid nutrient starvation effects. With this objective, dilutions with prewarmed fresh medium with or without selenite were made when required. For respiratory growth, YPGly medium was employed, with the same composition as YPD except that it contained $3 \%(\mathrm{w} / \mathrm{v})$ glycerol instead of glucose.

Growth determination. Total cell number was determined using a Coulter Z2 analyser, after $2 \%(\mathrm{w} / \mathrm{v})$ formaldehyde fixation of cell culture samples. Viable cells were quantified by plating appropriate dilutions of culture samples on YPD plates, and counting c.f.u. after 2 days incubation at $30{ }^{\circ} \mathrm{C}$. Sensitivity to selenite was also determined 
Table 1. Strains used in this study

\begin{tabular}{|c|c|c|}
\hline Strain & Genotype & Source and comments \\
\hline W303-1A & MATa ura3-1 ade2-1 leu2-3,112 trp1-1 his3-11,15 can1-1 & Wild-type \\
\hline MML736 & W303-1A grx2::LEU2 & Garcerá et al. (2006) \\
\hline MML751 & W303-1A grx1:: kanMX4 & Garcerá et al. (2006) \\
\hline MML752 & W303-1A grx1:: kanMX4 grx2:: LEU2 & Garcerá et al. (2006) \\
\hline MML1051 & MML752 [pMM902(tet $\left.\left.O_{7}-G R X 7^{*}\right)\right]:: U R A 3 \dagger$ & Integration of pMM902 in MML752 \\
\hline MML1052 & MML752 [pMM903 $\left(\right.$ tet $\left.\left._{7}-G R X 6^{*}\right)\right]::$ URA3 & Integration of pMM903 in MML752 \\
\hline MML1133 & W303-1A yca1:: kanMX4 & From the BY4741 background \\
\hline MML1139 & MML752 [pMM952(GRX5*)]:: URA3§ & Integration of pMM952 in MML752 \\
\hline MML1152 & MML752 [pMM958(GRX1)]:: URA3 & Integration of pMM958 in MML752 \\
\hline MML1157 & MML752 [pMM960( tet $\left.\left._{7}-G R X 7^{*} C 108 S\right)\right]::$ URA3 & Integration of pMM960 in MML752 \\
\hline MML1165 & W303-1A ndil:: kanMX4 & From the BY4741 background \\
\hline MML1166 & W303-1A aif1 : : kanMX4 & From the BY4741 background \\
\hline MML1167 & W303-1A cox12: : kanMX4 & From the BY4741 background \\
\hline CML235 & 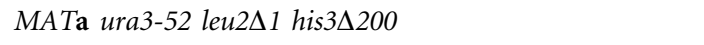 & Wild-type; Rodríguez-Manzaneque et al. (1999) \\
\hline MML1178 & CML235 grx1:: kanMX4 grx2:: LEU2 & This work \\
\hline MML1183 & MML1178 [pMM902 $\left(\right.$ tet $\left.\left._{7}-G R X 7^{*}\right)\right]:: U R A 3 \dagger$ & Integration of pMM902 in MML1178 \\
\hline
\end{tabular}

$\dagger G R X 7^{\star}:$ GRX7 ORF without codons 2-39.

$\ddagger G R X 6^{*}$ : GRX6 ORF without codons 2-39.

§GRX5*: GRX5 ORF without codons 2-23 (Rodríguez-Manzaneque et al., 2002).

in plate assays by spotting serial 1:10 dilutions of exponential cultures onto YPD plates containing sodium selenite, and recording growth after 2 days incubation at $30{ }^{\circ} \mathrm{C}$.

Cell death assays. About $2 \times 10^{6}$ cells from YPD medium cultures were centrifuged at room temperature, washed with synthetic SC medium (Sherman, 2002) and resuspended in $20 \mu \mathrm{l}$ fresh SC medium containing $200 \mu \mathrm{g} \mathrm{ml} \mathrm{m}^{-1}$ methylene blue or propidium iodide. Stained (dead) and unstained (live) cells were counted by phase-contrast microscopy. At least 200 cells were counted per sample.

\section{Terminal deoxynucleotidyl transferase dUTP nick end labelling} (TUNEL) assays. About $2 \times 10^{7}$ cells were harvested, washed with water and fixed with $500 \mu 3.7 \%(\mathrm{v} / \mathrm{v})$ formaldehyde in PBS for $30 \mathrm{~min}$ at room temperature. Cells were then washed with PBS and resuspended in $50 \mu \mathrm{l} \mathrm{PBS}$ with $300 \mu \mathrm{g} \mathrm{ml}^{-1}$ Zymolyase 100T (ICN Biomedicals). Incubation was carried out at $30{ }^{\circ} \mathrm{C}$, and was followed by phase-contrast microscopy until spheroplast formation was observed. Cells were then washed by gentle centrifugation, applied to polylysine-coated slide wells and allowed to settle for $15 \mathrm{~min}$ at room temperature. Excess liquid was removed, cells were washed with PBS and each well was incubated with $20 \mu \mathrm{l}$ permeabilization solution [0.1\% (v/v) Triton X-100 in $0.1 \%(\mathrm{w} / \mathrm{v})$ sodium citrate] for $2 \mathrm{~min}$ at $4{ }^{\circ} \mathrm{C}$. After two washes with PBS, $15 \mu$ TUNEL Reaction Mixture (In situ Cell Death Detection kit, Fluorescein, Roche Applied Science) was applied to each well, for DNA free $3^{\prime}-\mathrm{OH}$ terminus labelling with FITC-dUTP. The reaction was done following the kit instructions, with incubation at $37{ }^{\circ} \mathrm{C}$ for $1 \mathrm{~h}$. After three rinses with PBS, the preparation was dried for $10 \mathrm{~min}$ at room temperature and mounted with $4 \mu$ l Slowfade Gold antifade reagent (Molecular Probes). For scoring the percentage of cells with fluorescent nuclei, at least 200 cells were observed per sample, in an Olympus BZ51 fluorescence microscope with a U-MNBA3 filter for FITC emission. In parallel, positive controls were done which consisted of permeabilized cells treated for $10 \mathrm{~min}$ at room temperature with $0.1 \mu \mathrm{g} \mathrm{ml}^{-1}$ DNase I (Sigma).
Mutagenicity assays. Culture samples were taken, washed with synthetic SD medium (Sherman, 2002) and resuspended in the same medium. Equivalents between $2 \times 10^{6}$ and $2 \times 10^{7}$ cells were plated onto SD plates modified with the required auxotrophic supplements plus canavanine $\left(60 \mu \mathrm{g} \mathrm{ml}^{-1}\right)$. In parallel, appropriate dilutions were plated onto the same medium without canavanine, to determine the concentration of viable cells. The number of growing colonies on the respective plates was counted after 3 days incubation at $30{ }^{\circ} \mathrm{C}$, to calculate the fraction of viable cells which were canavanine-resistant.

4,8-Diamidino-2-phenylindole (DAPI) staining. Nuclei were stained with DAPI. About $1 \times 10^{7}$ cells were harvested, washed with PBS and fixed with $3.7 \%(\mathrm{v} / \mathrm{v})$ formaldehyde in PBS for $30 \mathrm{~min}$. After three washes with PBS, cells were incubated with DAPI $\left(2 \mu \mathrm{g} \mathrm{ml}^{-1}\right)$ in PBS in the dark, which was followed by a wash with PBS and fluorescence microscopy analysis.

Western blot analyses. Western blot analyses were done according to Bellí et al. (1998). Anti-Grx7p antibodies (Mesecke et al., 2008b) were employed at a 1:500 dilution.

Protein carbonylation analysis. Analysis of protein carbonylation after derivatization of carbonyl groups with dinitrophenylhydrazine (DNPH) was carried out as described in Molina et al. (2004), except that rabbit anti-DNPH antibodies (Sigma) were employed at $1: 2000$ dilution.

ROS determination. Dihydroethidium is a fluorescent probe for ROS detection that shows some selectivity for superoxide anion (Benov et al., 1998). About $10^{7}$ cells were harvested, washed with PBS and resuspended in $1 \mathrm{ml}$ PBS plus $0.1 \%(\mathrm{w} / \mathrm{v})$ glycerol. Fluorescence emission was measured at time 0 and then dihydroethidium (Sigma) was added $\left(5 \mu \mathrm{g} \mu \mathrm{l}^{-1}\right.$ final concentration). Fluorescence measurements were made at $5 \mathrm{~min}$ intervals for $30 \mathrm{~min}$, using a $\lambda_{\mathrm{ex}}$ of $520 \mathrm{~nm}$ and a $\lambda_{\mathrm{em}}$ of $590 \mathrm{~nm}$. The relative emission rate was calculated from the slope of the linear regression data plot. 


\section{RESULTS}

\section{Grx1p and Grx2p have overlapping roles in protecting against selenite toxicity in S. cerevisiae, and can be substituted by other GRXs}

It has been reported that a grx 1 grx 2 mutant of $S$. cerevisiae is hypersensitive to sodium selenite (Lewinska \& Bartosz, 2008). We confirmed this observation in the W303 genetic background employed in our experiments, and observed that the single grxl or grx2 mutants displayed the same
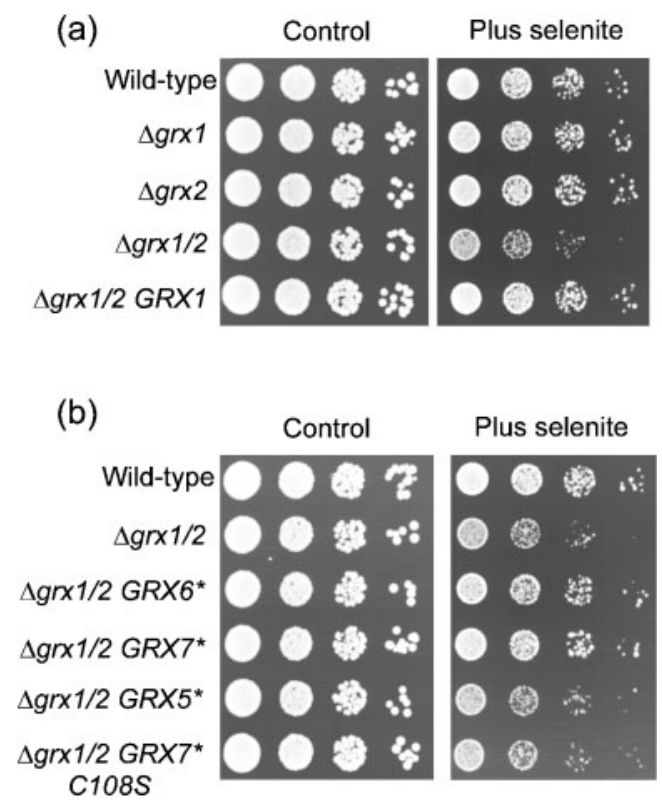

(c)

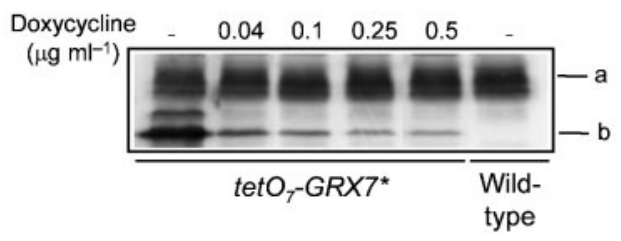

Fig. 1. Effect of $6 \mathrm{mM}$ sodium selenite on $S$. cerevisiae strains in plate growth assays. (a) The following strains were tested for growth on YPD plates without (control) or with selenite (2 days at $30{ }^{\circ} \mathrm{C}$ ): W303-1A (wild-type), MML751 ( $\Delta$ grx1), MML736

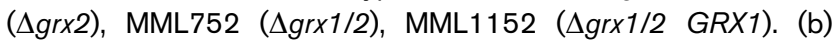
The following strains were tested for growth: W303-1A (wild-

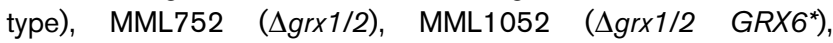
MML1051 ( $\Delta g r \times 1 / 2$ GRX7*), MML1139 ( $\operatorname{gr\times 1/2}$ GRX5*), MML1157 ( $\Delta$ grx1/2 GRX7*C108S). (c) Western blot analysis (30 $\mu \mathrm{g}$ total cell protein per lane) of MML1051 cells expressing both the native Grx7p protein (band a) and the truncated form of Grx7p (band b). The latter form was expressed from the chromosomally integrated plasmid pMM902, under the control of the $\operatorname{tet}_{7}$ promoter. In order to modulate expression from the tet $\mathrm{O}_{7}$ promoter, exponential-phase cell cultures in YPD medium at $30{ }^{\circ} \mathrm{C}$ were employed with the indicated concentrations of doxycycline. sensitivity as wild-type cells in plate growth assays (Fig. 1a), which indicates that the two GRXs have overlapping functions in protection against selenite toxicity. When the double mutant was transformed with an integrative plasmid (pMM958) that expressed GRX1 under its own promoter, the phenotype was rescued (Fig. 1a), demonstrating that the hypersensitivity of the mutant to selenite was exclusively caused by the absence of the two GRXs. Similar results were obtained with an integrative plasmid expressing GRX2 at physiological levels (results not shown).

Some yeast GRXs may have interchangeable activities, provided that compartmental barriers are eliminated (Molina et al., 2004). The sensitivity phenotype of the grx1 grx2 mutant allowed us to determine whether membrane-associated GRXs can carry out the functions of classical dithiol GRXs when the former are targeted to the cytosol. For cytosolic compartmentalization, we used constructions that expressed truncated forms of Grx6p or Grx7p without the transmembrane domain, under the control of the doxycycline-regulated $\operatorname{tet}_{7}$ promoter. The Grx6p and Grx7p forms that lack the transmembrane domain in fact localize to the cytosol (Izquierdo et al., 2008). These cytosolic versions conferred upon the double mutant almost the same level of resistance to selenite on YPD plates as that of wild-type cells (Fig. 1b). Although further studies are described here for Grx7p, similar rescuing properties were observed for Grx6p (data not shown). The protective function of Grx7p against selenite depended on its thiol oxidoreductase activity, since substitution of the cysteine residue of its CPYS active site by a serine abrogated this function (Fig. 1b). The possibility existed that the rescuing ability of Grx7p was caused by non-physiological overexpression of the protein. However, this did not seem to be the case, as Western analysis demonstrated that the levels of cytosolic Grx7p were similar to those of the native membrane-associated form of the protein expressed under its own promoter (Fig. 1c). As expected, doxycycline addition drastically reduced Grx7p levels. As demonstrated in a previous study (Izquierdo et al., 2008), cytosolic Grx7p ran in the gels in a homogeneous form, while the membrane-associated protein exhibited multiple bands due to $O$-glycosidic modifications (Fig. 1c). We also tested whether a monothiol GRX of the CGFS type, Grx5p, which normally localizes to mitochondria (Rodríguez-Manzaneque et al., 2002), is able to substitute for Grx1p and Grx2p when artificially localized to the cytosol. However, functional substitution did not occur, since the mitochondrial targeting sequenceless derivative of Grx5p did not rescue the selenite hypersensitivity of the grx1 grx2 mutant (Fig. 1b). Overall, the observations support the structural and biochemical similarity of Grx6p and Grx7p to dithiol GRXs, and are in accordance with previous results showing that Grxlp and Grx2p do not substitute for the mitochondrial function of Grx5p in the synthesis of iron-sulphur clusters (Molina et al., 2004). 


\section{Selenite causes non-apoptotic and apoptotic death in yeast cells}

To further characterize the effect of Se on yeast cells and the protective role of Grxlp/Grx2p, the growth rate of wild-type and grx1 grx2 mutant cells was quantified in liquid cultures in YPD medium (fermentative growth) in the presence of sodium selenite (Fig. 2a). In order to maintain exponential conditions for treated and nontreated cells during the experimental time-course, cultures were successively diluted into fresh medium with or without selenite when required (see Methods). The growth rate of treated wild-type cultures during the first $24 \mathrm{~h}$ of treatment was about $25 \%$ of the exponential growth rate of the respective untreated cultures. This was also the case for mutant cell cultures expressing cytosolic Grx7p. In contrast, during the same period of treatment the double mutant grew in the presence of selenite at a rate that was only $15 \%$ of that of untreated cultures. After $24 \mathrm{~h}$ of treatment, the growth of the three treated cultures became almost totally arrested, and the relative biomass concentration reached by the selenite-treated grx 1 gr $x 2$ cultures was about $15 \%$ of that of the other two treated cultures
(Fig. 2a, inset). These results confirm that cytosolic Grx7p rescues the double mutant phenotype, and also indicate that independently of the strain, growth only becomes totally arrested after $24 \mathrm{~h}$ in the presence of the toxic agent.

The above results could be due to a growth rate reduction caused by selenite or due to a death effect in part of the population. To distinguish between the two possibilities, we determined the fraction of live cells in cultures during $30 \mathrm{~h}$ of selenite treatment. As above, cultures were rediluted when required with fresh medium containing selenite to avoid growth effects from nutrient depletion. From the beginning of treatment, selenite caused a progressive accumulation of dead cells, to a larger extent in the grx1 grx2 mutant than in wild-type cells (Fig. 2b). After $30 \mathrm{~h}$ of treatment, only 25 and $12 \%$ of the cells remained viable in wild-type and grx grx cultures, respectively. The percentage of viable cells in selenitetreated mutant cultures expressing cytosolic Grx7p increased relative to the mutant, although it did not reach the levels of wild-type cultures (Fig. 2c). As a control, expression of GRX1 at physiological levels in an integrative plasmid (pMM958) in the chromosomal grxl grx2 (a)

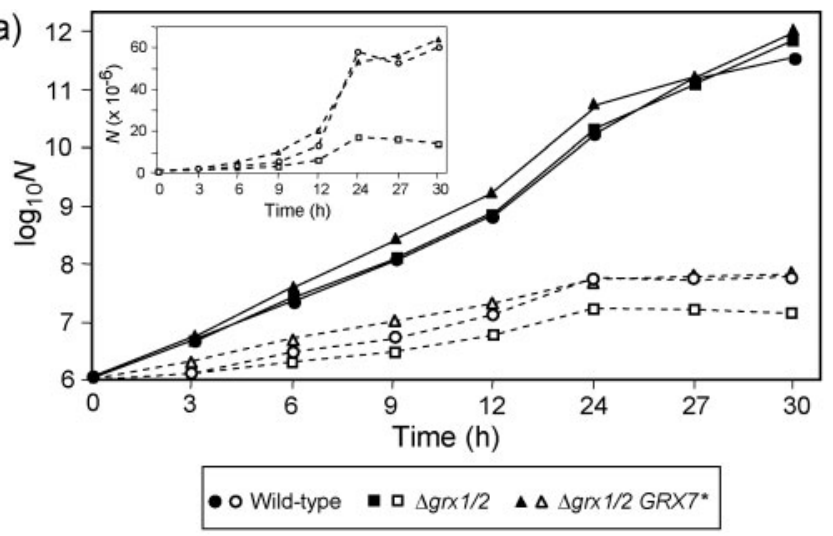

(b)

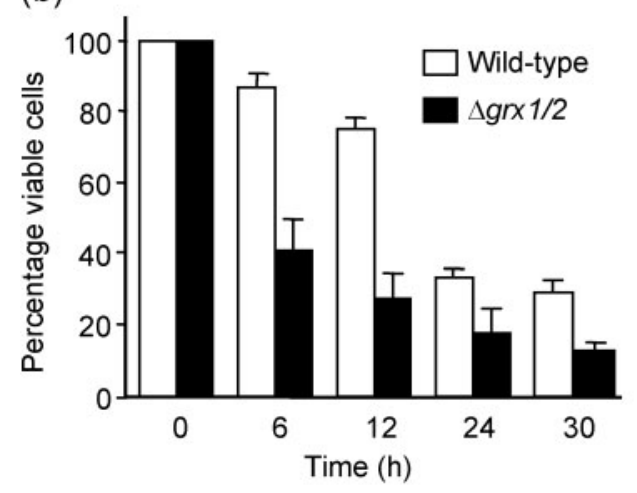

Fig. 2. Effect of $6 \mathrm{mM}$ sodium selenite on growth of wild-type (W303-1A), mutant $\Delta g r \times 1 / 2$ cells (strain MML752) and mutant cells expressing a truncated form of Grx7p as indicated in the text $\left(\Delta g r \times 1 / 2 G R X 7^{*}\right.$, strain MML1051). (a) Evolution of total cell number per millilitre $(N)$ in cultures growing in YPD medium at $30^{\circ} \mathrm{C}$ without (filled symbols, continuous lines) or with sodium selenite added at time 0 (empty symbols, dashed lines). The $N$ value at time 0 was $10^{6}$ cells $\mathrm{ml}^{-1}$, and cultures were diluted with fresh medium (without or with selenite) when they reached a concentration of $3-4 \times 10^{7}$ cells $\mathrm{ml}^{-1}$. The corresponding dilution factors were taken into account in plotting $N$ values. Inset: data for treated cultures plotted with a linear $y$ axis scale. Plots correspond to a representative experiment made in parallel with the three strains. (b) Percentage of viable cells in cultures of wild-type or mutant $\Delta g r \times 1 / 2$ cells after different times in the presence of sodium selenite. Total cell numbers and c.f.u. (viable cells) per millilitre were measured in parallel, to calculate the percentage of viable cells in the population. Viability was determined in plating assays on YPD. Bars, mean and SD of three independent experiments. (c) Percentage of viable cells in cultures of wild-type, $\Delta g r \times 1 / 2$, $\triangle g r \times 1 / 2$ GRX7* or $\Delta g r \times 1 / 2$ GRX1 (strain MML1152) cells after $12 \mathrm{~h}$ of selenite treatment, relative to the viability of wild-type cells $(100 \%)$. Bars, mean and SD of three independent experiments. 
background rescued the viability of selenite-treated cultures to the same levels as those of wild-type cells (Fig. 2c).

We next determined the type of death caused by selenite in S. cerevisiae, and how the absence of Grxlp and Grx2p influences the death rate. Different markers can be used in yeast cells to distinguish between non-apoptotic and apoptotic death. In the case of non-apoptotic death, the process is accompanied by an increase in plasma membrane disorganization and permeability to staining agents such as propidium iodide and methylene blue (Dudgeon et al., 2008; Zhang et al., 2006). In experiments using the latter agent, plasma membrane-compromised cells began appearing at early times of treatment and progressively increased in number (Fig. 3). Up to $18 \mathrm{~h}$ of treatment, the proportion of dead cells in the population was significantly higher in the double mutant than in wild-type cells. The differences were statistically significant, as determined by a Kruskal-Wallis test, and expression of cytosolic Grx7p reduced the proportion of methylene blue-permeable dead cells. At later times of treatment $(24 \mathrm{~h})$, the percentage of cells with compromised plasma membranes did not show statistically significant differences among the three cultures (around $40 \%$ in all cases). Similar values were obtained with propidium iodide as a non-apoptotic death marker (data not shown). This therefore indicates that the functions of Grxlp and Grx2p make cells less susceptible to the early toxic events induced by selenite that lead to non-apoptotic cell death. In all cases, $70 \pm 3 \%$ of the plasma membrane-compromised cells had buds, which is a percentage very similar to that of the entire population.

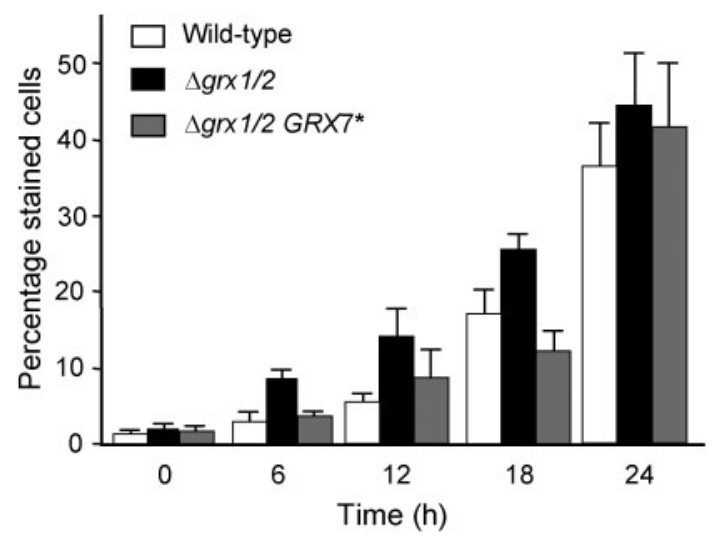

Fig. 3. Effect of $6 \mathrm{mM}$ sodium selenite (added at time 0 at a culture concentration of $10^{7}$ cells $\mathrm{ml}^{-1}$ ) on the percentage of membrane-compromised cells (stained by methylene blue) in cultures of wild-type cells (W303-1A), mutant $\Delta$ grx1/2 cells (MML752) and mutant cells expressing the truncated form of Grx7p ( $\Delta$ grx1/2 GRX7*, MML1051) in YPD medium at $30{ }^{\circ} \mathrm{C}$. Cultures were diluted with fresh medium with or without selenite when they reached a concentration of $3-4 \times 10^{7}$ cells $\mathrm{ml}^{-1}$. Microscopy analyses were done when cultures were at a concentration of $1-2 \times 10^{7}$ cells $\mathrm{ml}^{-1}$. Bars, mean and SD of at least three independent experiments.
This suggests that non-apoptotic death does not specifically affect cells at a particular cell cycle stage.

We also determined whether selenite-treated $S$. cerevisiae cells displayed apoptotic markers. A marker that appears in the initial stages of yeast apoptosis is nuclei degeneration (half-ring-shaped) followed by fragmentation (Madeo et al., 1999), which can be demonstrated by DAPI staining. In fact, a few abnormal nuclei began to appear in wild-type cells after $12 \mathrm{~h}$ of selenite treatment, while after $24 \mathrm{~h}$ a significant fraction of the cell population contained fragmented nuclei (Fig. 4a). This pointed to apoptotic death caused by selenite. In order to quantify apoptotic cells in wild-type and $g r x 1$ grx 2 cells treated with selenite, we used as an apoptotic marker the cleavage of chromosomal DNA producing free $3^{\prime}-\mathrm{OH}$ termini, which is widely used in yeast cells. These DNA termini can be detected by the TUNEL assay in the form of fluorescent nuclei (Madeo et al., 1999, 2002). TUNEL-positive wildtype cells appeared at a significant proportion (more than $40 \%$ of the population) after $24 \mathrm{~h}$ of treatment (Fig. $4 \mathrm{~b}, \mathrm{c}$ ). At this time, no differences were observed in the percentage of budded cells between TUNEL-positive and -negative cells (data not shown). When we quantified cultures of the grx 1 grx 2 mutant expressing or not expressing the cytosolic Grx7p form (Fig. 4c), no significant statistical differences (as determined with a Kruskal-Wallis test) in the proportion of TUNEL-positive cells were observed compared with the wild-type strain. This confirms that selenite also causes apoptotic death after long exposure times, and that Grxlp and Grx $2 p$ do not seem to protect against this type of death.

\section{Selenite-mediated non-apoptotic and apoptotic dead cells are independent populations}

The possibility existed that membrane-compromised and TUNEL-positive populations overlapped; in other words, that the death markers that we employed did not inform us about the existence of two independent death events, at least after longer treatment times. However, two different experimental lines of evidence supported the independence of the two types of death in selenite-treated yeast cells, in addition to the above-described differential dependence on the functions of Grxlp and Grx2p. First, we treated wildtype cells for $24 \mathrm{~h}$ with lower selenite concentrations ( 3 and $4 \mathrm{mM}$ ). Under these conditions a significant number of cells still displayed non-apoptotic death markers, while the proportion of TUNEL-positive cells remained almost negligible (Fig. $4 \mathrm{~d}$ ). After the $24 \mathrm{~h}$ treatment with $4 \mathrm{mM}$ selenite, almost $14 \%$ of the cells were membranecompromised, while fewer than $2 \%$ of the cells displayed an apoptotic marker. Second, we treated wild-type cells with $6 \mathrm{mM}$ selenite for $24 \mathrm{~h}$ and then simultaneously stained them with propidium iodide and DAPI, without previous formaldehyde fixation. Under these conditions, only about $10 \%$ of the cells showing abnormal nuclear morphology were also permeable to propidium iodide. 
(a)

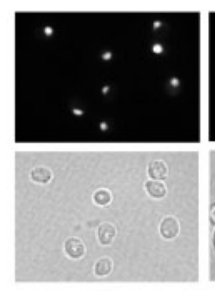

0

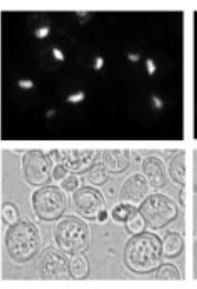

12

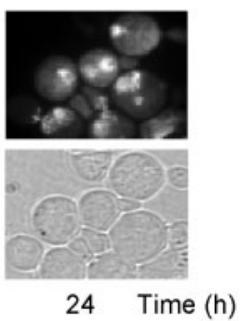

(c)

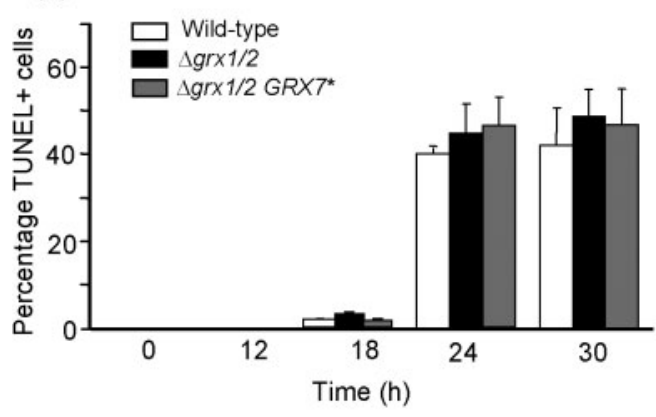

(b)
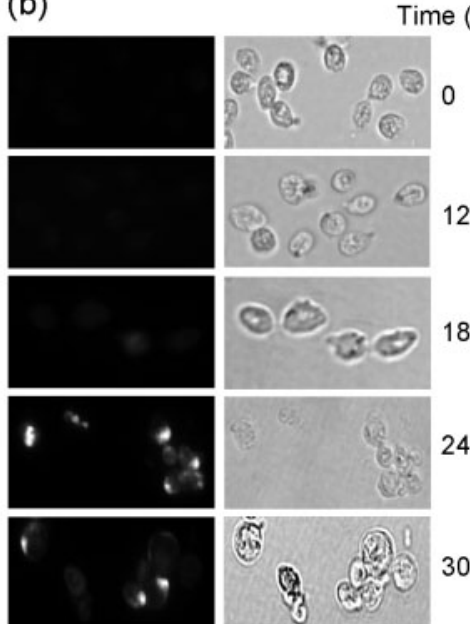

12
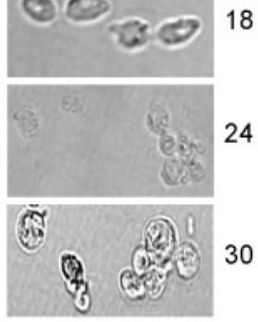

(d)

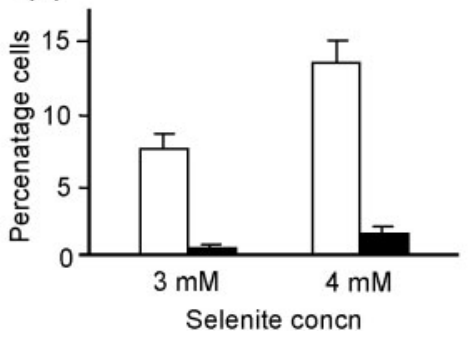

Fig. 4. Effect of sodium selenite on the appearance of apoptotic markers in cultures of wild-type cells (W303-1A), mutant $\Delta g r \times 1 / 2$ cells (MML752) and mutant cells expressing the truncated form of Grx7p ( $\operatorname{rrx} 1 / 2$ GRX7*, MML1051) in YPD medium at $30{ }^{\circ} \mathrm{C}$. Treatment conditions and dilution with prewarmed medium were as indicated in Methods and the legend to Fig. 2. (a) DAPI staining of nuclei of wild-type cells at the indicated times after addition of $6 \mathrm{mM}$ sodium selenite at time 0 (upper panels). Lower panels show the corresponding phase-contrast images. (b) TUNEL staining (left panels) and the corresponding phasecontrast (right panels) images of wild-type cells treated with $6 \mathrm{mM}$ sodium selenite for the indicated times. (c) Percentage of TUNEL-positive cells in cultures of the indicated strains after different times of $6 \mathrm{mM}$ sodium selenite treatment. Bars, mean and SD of at least three independent experiments. (d) Percentage of TUNEL-positive (black bars) and methylene blue-permeable (white bars) cells in cultures of wild-type cells treated for $24 \mathrm{~h}$ with 3 or $4 \mathrm{mM}$ sodium selenite. Bars, mean and SD of three independent experiments.

Taken together, these observations support the idea that the apoptosis-like nuclear alterations in selenite-treated cells are not secondary to long-term membrane alterations in dead cells, and that there is only a minor overlap between non-apoptotic and apoptotic dead cell populations.

\section{Selenite-mediated apoptosis requires Aif1p activity}

The yeast Ycalp metacaspase mediates apoptosis induced by hydrogen peroxide (Khan et al., 2005; Madeo et al., 2002) or other stimuli (Madeo et al., 2004; Mazzoni \& Falcone, 2008). However, agents such as copper provoke apoptosis by a Ycalp-independent mechanism (Liang \& Zhou, 2007). We therefore studied whether apoptosis induced by selenite depends on Ycalp. A null ycal mutant showed a slightly reduced percentage of TUNEL-positive cells compared with the wild-type strain upon treatment with the agent (Fig. 5a), and its growth was not significantly affected in plate assays in the presence of selenite (data not shown). This indicates that Ycalp has only a modest role in mediating apoptotic death by selenite.

Mitochondrial functions are required for apoptosis induction by different agents (Pereira et al., 2008). Thus, mutational disruption of the $S$. cerevisiae mitochondrial electron transport chain reduces apoptosis caused by copper and manganese (Liang \& Zhou, 2007), amiodarone (Pozniakovsky et al., 2005), acetic acid (Ludovico et al., 2002), hyperosmotic stress (Silva et al., 2005) and chronological ageing (Li et al., 2006). We tested how the absence of Ndilp (mitochondrial inner membrane-associated $\mathrm{NADH}$ dehydrogenase) or Cox12p (part of complex IV in the electron transport chain) affected selenite-induced apoptosis. The ndil mutant displayed a moderate reduction in TUNEL-positive cells, while the percentage of 
(a)

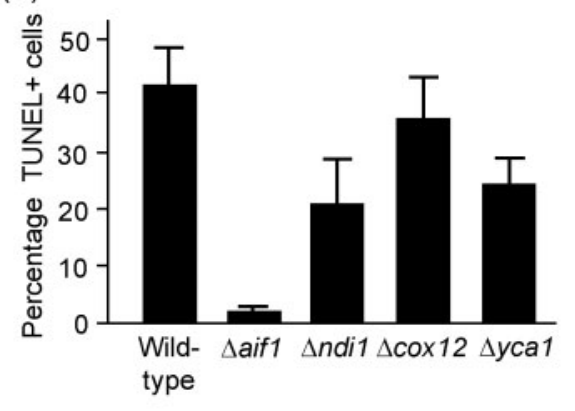

(b)

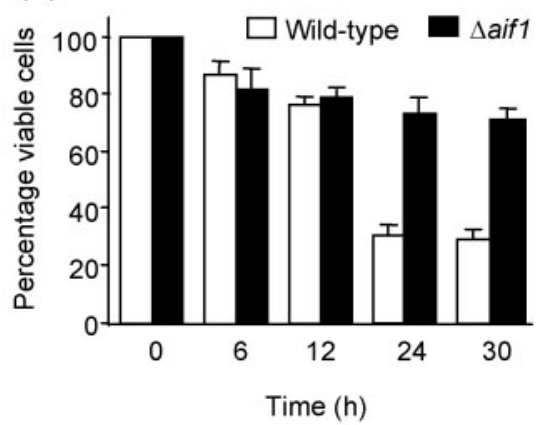

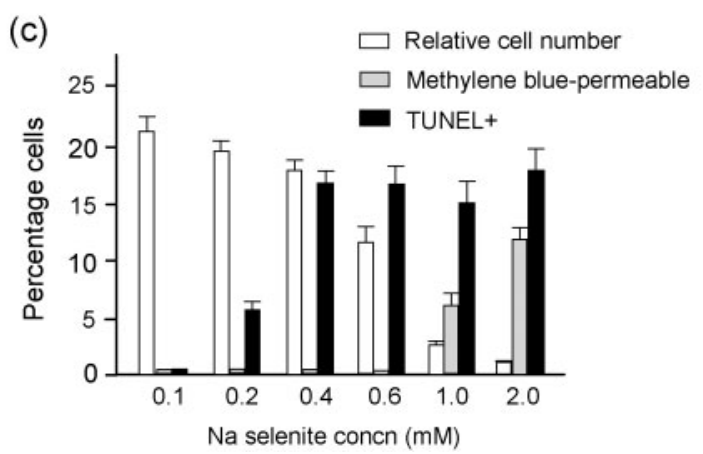

Fig. 5. Selenite-induced apoptosis in S. cerevisiae and mitochondrial functions. (a) Percentage of TUNEL-positive cells after $24 \mathrm{~h}$ of $6 \mathrm{mM}$ sodium selenite treatment in YPD medium at $30{ }^{\circ} \mathrm{C}$. Cultures of wild-type cells (W303-1A) and the following mutants were analysed: MML1166 ( $\Delta$ aif1), MML1165 ( $\Delta$ ndi1), MML1167 ( $\Delta$ cox 12), MML1133 ( $\Delta y$ ca 1). Treatment conditions and dilution with prewarmed medium were as indicated in Methods and the legend to Fig. 2. Bars, mean and SD of three independent experiments. (b) Cell viability in MML1166 ( $\Delta$ aif1) and W303-1A (wild-type) cultures after different times of 6 mM sodium selenite treatment in YPD medium at $30{ }^{\circ} \mathrm{C}$. The percentage of viable cells at each time point was calculated as described in Methods. Bars, mean and SD of three independent experiments. (c) Effect of sodium selenite at the indicated concentrations on wild-type cells growing in YPGly medium at $30{ }^{\circ} \mathrm{C}$. The following parameters were determined after $24 \mathrm{~h}$ of treatment: relative total cell number (treated/untreated cultures), percentage of methylene blue-permeable cells and percentage of TUNEL-positive cells. Bars, mean and SD of three independent experiments.

TUNEL-positive cells in the cox12 mutant was similar to that in the wild-type strain (Fig. 5a). No differences in growth were observed in the two mutants compared with wild-type cells in a plate growth assay in the presence of selenite (data not shown). Therefore, disruption of the mitochondrial electron transport chain has a moderate or no effect on induction of apoptosis by selenite.

The yeast Aiflp protein is the homologue of apoptosisinducing factor (AIF), a mammalian mitochondrial flavoprotein that upon apoptotic stimuli translocates into the nucleus, where it plays a role in the caspase-independent induction of apoptosis (Susin et al., 1999). AIF has oxidoreductase activity, although conflicting data exist concerning whether this and the apoptosis-induction activity are functionally independent or not (Churbanova \& Sevrioukova, 2008; Miramar et al., 2001). In S. cerevisiae, Aiflp mediates apoptosis induced by oxidative stress, acetic acid or chronological ageing (Wissing et al., 2004), and it is also important for survival after manganese treatment (Liang \& Zhou, 2007). In contrast, it does not participate in hyperosmotic stress-induced apoptosis (Silva et al., 2005). Upon selenite treatment, the percentage of TUNELpositive cells was near zero in a null aif1 mutant (Fig. 5a). In accordance with this, growth inhibition by selenite was slightly lower in the mutant compared with the wild-type in a plate growth assay (data not shown). In addition, we compared the percentages of viable cells in liquid cultures of wild-type and aif1 strains (Fig. 5b). At the initial times after selenite addition no differences were observed between the two strains, while after extended treatment times $(24$ and $30 \mathrm{~h}$ ) cell viability was 2.5 - to threefold higher in the mutant. Considering the kinetics in Fig. 2(b), we can conclude that the parallelism between the two strains only occurs in the non-apoptotic death phase, while during apoptotic death the aif1 cells are not further affected by selenite. Summarizing, Aiflp seems to be a mediator of apoptosis induced by selenite in yeast cells.

To further investigate the participation of mitochondrial functions in selenite-mediated apoptosis, we analysed the effect of this agent on yeast cells growing under respiratory 
conditions (YPGly medium). Much lower concentrations were required than in glucose-based medium to reach similar growth inhibition levels (Fig. 5c). However, at concentrations lower than $0.2 \mathrm{mM}$, growth inhibition by selenite was exclusively due to growth rate reduction, since practically all cells in the population remained viable (as determined by plate growth assays and comparison with total cell determinations; data not shown). Also, in contrast with the effects in YPD medium, selenite did not cause the appearance of membrane-permeable dead cells at concentrations that provoked apoptotic death (Fig. 5c). Only at selenite concentrations of $1 \mathrm{mM}$ or higher were methylene blue-stained cells observed. That is, under respiratory conditions, apoptotic death by selenite precedes other death effects. Mutants lacking Ycalp or Ndilp displayed levels of TUNEL-positive cells about $50 \%$ those of wildtype cells (data not shown), which indicates that in YPGly medium selenite-induced apoptosis is also only partially dependent on Ycalp or Ndilp. We could not determine the role of Aif1p under these conditions, as the aifl mutant showed extremely defective growth in YPGly medium.

\section{Selenite provokes an increase of protein carbonylation}

Protein carbonylation is a consequence of oxidative stress of yeast cells (Cabiscol et al., 2000), and can be used as a marker of protein damage by oxidants. We performed carbonylation assays with total cell extracts from wild-type and grx 1 grx 2 cultures after different times of selenite treatment in YPD medium (Fig. 6a). No differences were observed between the two strains in non-treated cultures and at initial times of treatment. However, after 18 and $24 \mathrm{~h}$, selenite caused more extensive protein carbonylation in the double mutant than in wild-type cells. Expression of cytosolic Grx7p in the mutant abolished such differences (Fig. 6a). Loading controls (Coommassie blue staining of gels) indicated that approximately the same protein amount was loaded in all lanes. We conclude that the accumulation of carbonyl modifications in proteins could be a consequence of the ROS generated by selenite.

Diverse studies have shown that apoptotic cells can be a source of ROS, and therefore of oxidative damage (Perrone et al., 2008). Consequently, we determined protein carbonylation in aif 1 cells after $24 \mathrm{~h}$ of selenite treatment, compared with wild-type cells. Both wild-type and aif1 cells displayed considerable protein carbonylation in gels upon treatment, although the levels were lower in the mutant even at the $7 \mathrm{mM}$ selenite concentration employed in this experiment (Fig. 6b). Therefore, apoptosis inhibition reduces protein carbonyl levels, suggesting that a fraction of the protein carbonyl groups which accumulate after prolonged treatment with selenite result from ROS generated by apoptotic cells.

To confirm intracellular ROS accumulation after longer times of selenite treatment, we employed dihydroethidium as a fluorescent probe for ROS, which has some selectivity

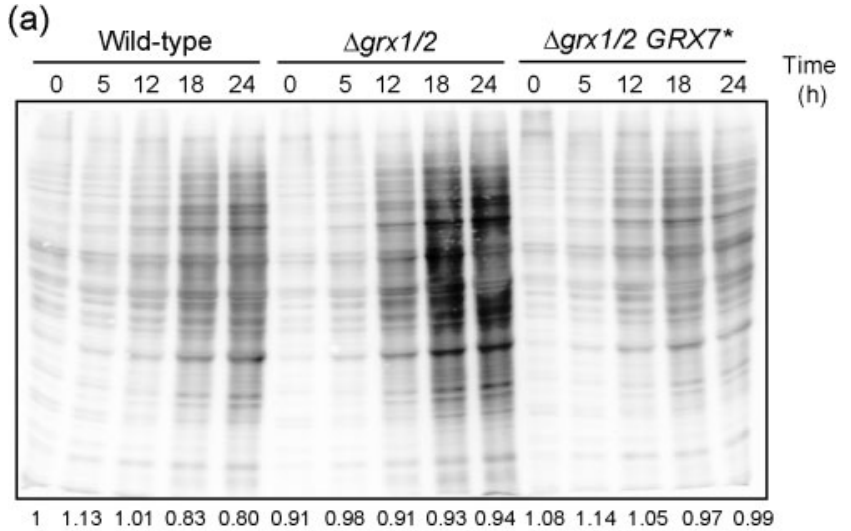

(b)
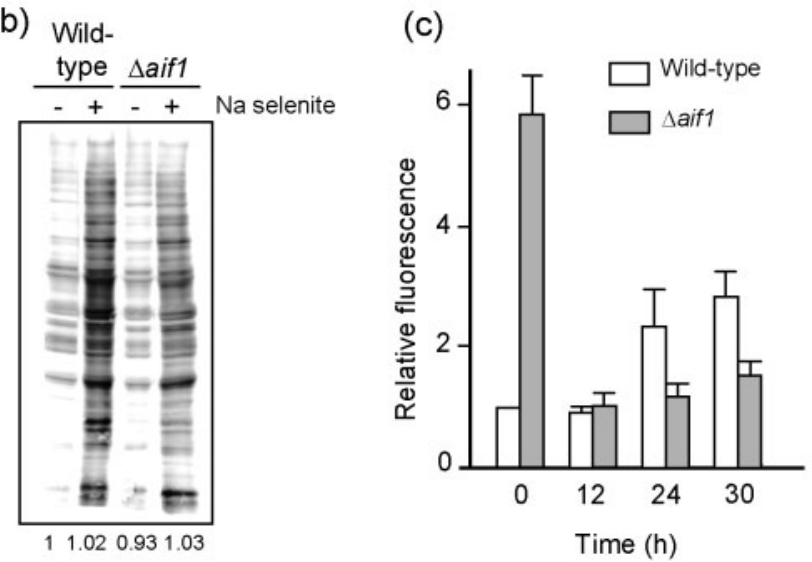

Fig. 6. Accumulation of carbonylated proteins and ROS in cultures of wild-type cells (W303-1A), mutant $\Delta g r \times 1 / 2$ cells (MML752), mutant cells expressing the truncated form of Grx7p ( $\Delta$ grx 1/2 GRX7*, MML1051) and $\Delta$ aif1 cells (MML1166). Initial treatment conditions and dilution with prewarmed medium were as indicated in Methods and the legend to Fig. 2. (a, b) Western blot analysis of protein carbonylation with anti-DNPH antibodies. Cell extracts were obtained from cultures of the indicated strains after different times of treatment with $6 \mathrm{mM}$ (a) or $7 \mathrm{mM}$ (b) sodium selenite in YPD medium at $30{ }^{\circ} \mathrm{C}$. Each lane was loaded with $10 \mu \mathrm{g}$ protein. Numbers under each lane indicate the relative amount of protein (with respect to wild-type cells at time 0) after scanning and densitometric quantification of the Coommassie blue-stained blotted membranes. (c) Fluorescence emission rate of cells to which dihydroethidium had been added as described in Methods. Cell samples were taken from cultures after the indicated times of $6 \mathrm{mM}$ selenite treatment. Values were made relative to the value of the fluorescence emission rate of wild-type cells before selenite addition. Bars, mean and SD of three independent experiments.

for superoxide anions (Benov et al., 1998). In wild-type cells, fluorescence emission increased two- to threefold (relative to time 0) only after $24 \mathrm{~h}$ in the continuous presence of selenite (Fig. 6c), that is, in parallel to the accumulation of apoptotic cells. At shorter treatment times, fluorescence emission due to ROS accumulation remained at levels similar to those of untreated cells. Such 
fluorescence emission after longer treatment times was significantly lower in the aif1 mutant (Fig. 6c). Remarkably, untreated exponentially growing aifl cells contained abnormally high intracellular levels of ROS, which may be related to disruption of the mitochondrial function of Aiflp in the mutant. Overall, these results support the contention that selenite-induced apoptotic cells are a source of ROS.

\section{Selenite mutagenicity is higher in the absence of Grx1 and Grx2}

We also determined Se-mediated genotoxicity in the grxl grx2 mutant and in wild-type cells, based on the appearance of canavanine-resistant $\left(\mathrm{can}^{\mathrm{R}}\right)$ mutants among the population of viable cells. Since the genetic background (W303) employed in the above experiments was already $\mathrm{can}^{\mathrm{R}}$, the following experiments were done in a different background of canavanine-sensitive wild-type cells and their corresponding grx1 grx2 derivative. The effect of selenite on the cell viability in this new background was similar to that shown in Fig. 2(b) for the respective W303 background strains (data not shown). As expected from Pinson et al. (2000), the proportion of wild-type viable cells which became can ${ }^{\mathrm{R}}$ increased with the duration of selenite treatment, confirming the mutagenicity of selenite under our experimental conditions (Fig. 7a). However, the proportion of $\mathrm{can}^{\mathrm{R}}$ mutants among viable cells was considerably higher in the $g r x 1 g r \times 2$ strain, especially at the earlier times of treatment. This confirmed that Grxlp and Grx2p also protect against selenite-caused genotoxicity. In a double mutant expressing the cytosolic version of Grx7p, the frequency of $\mathrm{can}^{\mathrm{R}}$ mutants was similar to that of wildtype cells (Fig. 7b), confirming that expression of Grx7p in the cytosol also suppresses the increased genotoxicity of selenite in the grx1 grx2 mutant.

\section{DISCUSSION}

Unlike in higher organisms, Se is not an essential oligoelement for yeast cell growth. Instead, high concentrations of Se cause genotoxicity in S. cerevisiae. The more toxic form of Se is selenide, which can be formed either outside or inside the cell from other Se forms, such as selenite (Tarze et al., 2007). Oxidation of selenide may generate superoxide, which can then be converted into other ROS to oxidize cellular components (Chen et al., 2007; Spallholz, 1997). Analysis of the sensitivity to Se of a large collection of $S$. cerevisiae null mutants indicates that the majority of hypersensitive mutants are affected in DNA repair functions (Seitomer et al., 2008), supporting the importance of DNA damage in Se toxicity.

In this work, we show that during fermentative growth, selenite causes non-apoptotic death at initial times of treatment, while longer treatment times induce apoptosis. This contrasts with peroxide-induced apoptosis in yeast (Madeo et al., 1999). In the latter case, low oxidant doses cause apoptosis, while a more intense stress produces socalled necrotic death. In the case of selenite, lowering the concentration does not increase the apoptosis rate. However, the experimental conditions were different for the two studies: while a single dose of peroxide was given (Madeo et al., 1999), in the case of selenite the concentration (a)

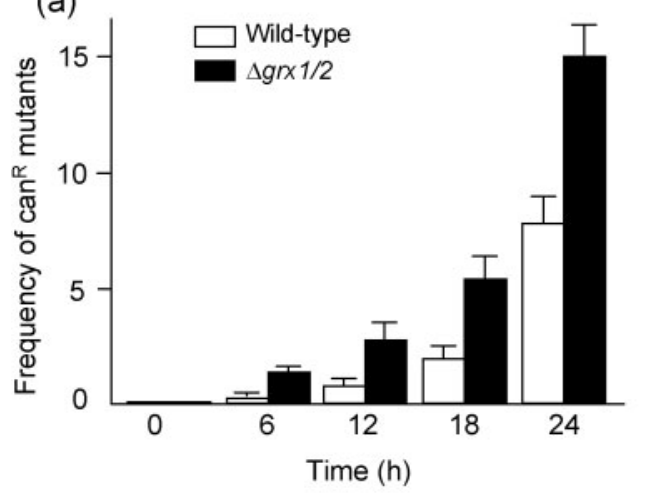

(b)

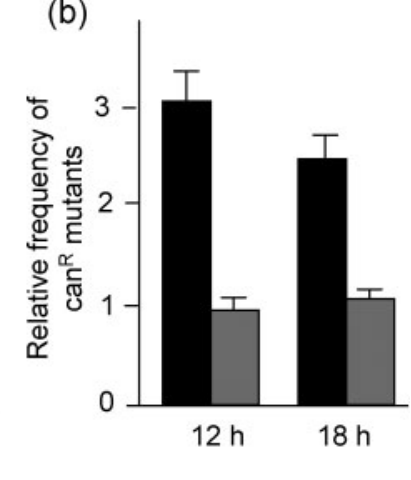

Fig. 7. Effect of sodium selenite on the appearance of canavanine-resistant mutants. (a) Wild-type (CML235) and $\Delta g r \times 1 \quad \Delta g r \times 2$ (MML1178) cells growing exponentially in YPD medium were treated at time 0 with $6 \mathrm{mM}$ sodium selenite, and at the indicated times samples were taken to determine in parallel the concentration of viable cells and the number of canavanine-resistant $\left(\operatorname{can}^{R}\right)$ mutants. Initial treatment conditions and dilution with prewarmed medium were as indicated in Methods and the legend to Fig. 2. Bars represent the frequency of $\mathrm{can}^{\mathrm{R}}$ mutants per $10^{5}$ viable cells (mean plus SD, three independent experiments). (b) The same strains as above plus the MML1183 mutant ( $\Delta$ grx1 $\Delta$ grx2 GRX7*) were grown in YPD and treated for 12 and $18 \mathrm{~h}$ with $6 \mathrm{mM}$ sodium selenite, before determination of the concentration of viable cells and the number of $\mathrm{can}^{\mathrm{R}}$ mutants. Bars represent the frequency of $\operatorname{can}^{R}$ cells in the two mutant strains relative to the wild-type strain (mean plus SD, three independent experiments). 
was maintained in the presence of the cells for longer times by repeated dilution with prewarmed medium containing the agent. At earlier treatment times with selenite (up to $18 \mathrm{~h}$ ), when the appearance of apoptotic markers was negligible, the observed viability decrease can be attributed to non-apoptotic death. At these earlier times, the percentage of dead cells as determined by plate assays was higher than the percentage of methylene blue-permeable cells, suggesting that some of the dead cells initially maintain their plasma membrane integrity. In any case, the population fraction of membrane-compromised cells increases steadily during treatment. In contrast to the effects on cells growing by fermentative metabolism, during respiratory growth low doses of selenite preferentially provoke apoptotic death, and non-apoptotic necrotic-like death only occurs at high doses of the agent, a situation reminiscent of peroxide death effects.

Grxlp and Grx2p have an overlapping role in protection against selenite-induced non-apoptotic death. A protective role against selenate (another toxic form of Se) has been reported for the Grxlp homologue in a cyanobacterium (Marteyn et al., 2009). We can only speculate about the function of the two yeast GRXs in relation to Se toxicity. Considering the redox regulatory role of GRXs with respect to protein cysteine residues, one obvious possibility is that Grxlp and Grx2p target proteins important for protection against selenite damage. Given the genotoxicity of selenite at the concentrations used in this study, some of the proteins involved in DNA repair and damage tolerance would be candidates for regulation by Grxlp/Grx $2 p$ activity. Alternatively, Grxlp and Grx2p could have a more non-specific role, perhaps based on their peroxidase activity (Collinson et al., 2002). In fact, high concentrations of selenite generate ROS in many cell types (Letavayová et al., 2006), and here we have shown that it causes timeand concentration-dependent protein carbonylation and ROS accumulation, which are indicative of intracellular oxidative stress. That selenite-induced redox disturbance is important for yeast cell growth is supported by the fact that antioxidants such as $\mathrm{N}$-acetylcysteine rescue the growth defects (Lewinska \& Bartosz, 2008).

The importance of GSH-mediated protection against Se is confirmed by observations from two global analyses in $S$. cerevisiae: (i) the overrepresentation of mutants in GSHmediated pathways among those mutants displaying selenite hypersensitivity (Seitomer et al., 2008); and (ii) the transcriptional induction of genes involved in these same pathways upon selenite treatment (Salin et al., 2008). In this context, decreasing the ratio between GSH and oxidized glutathione after selenite-induced oxidative stress would influence cell viability. In addition, the latter transcriptomic study suggests that selenite also influences intracellular iron homeostasis by interfering with mitochondrial iron-sulphur cluster synthesis (Salin et al., 2008). The results of the present study demonstrating the importance of GSH-dependent Grx1p and Grx2p activity for protection against non-apoptotic death emphasize the role of GSH in defence against Se toxicity.

When targeted to the cytosol, Grx6p and Grx7p rescue the accumulation of membrane-compromised cells in the grx 1 grx2 mutant, as well as the accumulation of carbonylated proteins and the mutagenicity rate, to wild-type levels. This proves that their function as GRXs can protect against Se toxicity. Thus, compartmental barriers do not necessarily correlate with functional barriers, as is also the case for other GRXs (Molina et al., 2004). Our observations also show that protection against selenite toxicity by GRXs requires a single active-site cysteine and therefore a monothiol mechanism of action. Remarkably, deglutathionylation of mixed disulphides between GSH and cysteine thiol groups of proteins only requires the most N-terminal cysteine of the GRX active site (Bushweller et al., 1992). This is also the case for Grxlp in defence against the action of selenite. Therefore, the possible functions of Grxlp and Grx2p could be related to redox repair of glutathionylated cysteine residues produced under selenite stress.

S. cerevisiae cells which survive initial non-apoptotic death in YPD medium may suffer apoptotic death after longer times of selenite treatment. Grx1p and Grx2p do not play a protective role against this type of death, which is also not affected by cytosolic expression of Grx7p. Therefore, hyperaccumulation of oxidatively damaged proteins cannot be the signal that triggers selenite-induced apoptosis. Several metals and metalloids are inductors of apoptosis in yeast cells, through mechanisms which may involve diverse intermediates (Gomes et al., 2008; Liang \& Zhou, 2007). In the case of selenite, neither Ycalp metacaspase nor a functional mitochondrial electron transport chain plays a major role in apoptosis induction, a situation which extends to apoptotic death during respiratory growth. In mammalian cells, AIF and AMID (AIF-homologous mitochondrionassociated inducer of death) are mediators of caspaseindependent apoptosis (Cande et al., 2002; Wu et al., 2002). Yeast Ndilp is homologous to mammalian AMID (Li et al., 2006). In the absence of Ndilp there is only a moderate reduction of apoptosis in selenite-treated cells. On the other hand, Aiflp seems to be central to apoptosis induction by selenite in S. cerevisiae. This is similar to apoptosis induction by the antimicrobial peptide dermaseptin S3 in yeast, which also depends on Aiflp but not on Ycalp (Morton et al., 2007). The in vivo role of mammalian AIF is a matter of debate. In parallel to (or related to) its apoptosis-promoting function, AIF is important for mitochondrial oxidative phosphorylation (Modjtahedi et al., 2006; Vahsen et al., 2004). In accordance with this, inhibiting AIF expression causes intracellular ROS accumulation in human cell lines (Apostolova et al., 2006). We have also observed ROS hyperaccumulation in the $S$. cerevisiae aif1 mutant during exponential growth, which supports a mitochondrial function for yeast Aiflp related to electron transport. In contrast, the aif1 mutant displays reduced accumulation of carbonylated proteins and of ROS after longer times of selenite treatment in YPD medium 
compared with wild-type cells, supporting the contention that the apoptotic cells are a source of the oxidative stress generated in that situation. Apoptotic S. cerevisiae cells resulting from a hyperosmotic stress are also a source of ROS (Silva et al., 2005).

Summarizing, selenite causes cell death through several mechanisms, including apoptosis, and GRX activity is important to protect cells against non-apoptotic death at earlier incubation times, pointing to the importance of redox control of proteins to overcome Se toxicity. Characterization of the specific protein targets will provide information about the function of GRXs in this type of stress.

\section{ACKNOWLEDGEMENTS}

We thank Joaquim Ros for critical reading of the manuscript, María Pérez-Sampietro for helping in some experiments, Johannes $\mathrm{M}$. Herrmann for the gift of antibodies, and Mireia Aresté for technical assistance. This work was supported by grants BFU2007-62703 and CSD2007-0020 (Ministerio de Ciencia e Innovación) to E. H. A. I. is the recipient of a grant from Ministerio de Ciencia e Innovación, Spain.

\section{REFERENCES}

Apostolova, N., Cervera, A. M., Victor, V. M., Cadenas, S., SanjuánPla, A., Alvarez-Barrientos, A., Espulgues, J. V. \& McCreath, K. J. (2006). Loss of apoptosis-inducing factor leads to an increase in reactive oxygen species, and an impairment of respiration that can be reversed by antioxidants. Cell Death Differ 13, 354-357.

Belli, G., Gari, E., Piedrafita, L., Aldea, M. \& Herrero, E. (1998). An activator/repressor dual system allows tight tetracycline-regulated gene expression in budding yeast. Nucleic Acids Res 26, $942-$ 947.

Benov, L., Sztejnberg, L. \& Fridovich, I. (1998). Critical evaluation of the use of hydroethidine as a measure of superoxide anion. Free Radic Biol Med 25, 826-831.

Bushweller, J. H., Aslund, F., Wuthrich, K. \& Holmgren, A. (1992). Structural and functional characterization of the mutant Escherichia coli glutaredoxin (C14-S) and its mixed disulfide with glutathione. Biochemistry 31, 9288-9293.

Cabiscol, E., Piulats, E., Echave, P., Herrero, E. \& Ros, J. (2000). Oxidative stress promotes specific protein damage in Saccharomyces cerevisiae. J Biol Chem 275, 27393-27398.

Cande, C., Cecconi, F., Dessen, P. \& Kroemer, G. (2002). Apoptosisinducing factor (AIF): key to the conserved caspase-independent pathways of cell death. J Cell Sci 115, 4727-4734.

Chen, J. J., Boylan, L. M., Wu, C. K. \& Spallholz, J. E. (2007). Oxidation of glutathione and superoxide generation by inorganic and organic selenium compounds. Biofactors 31, 55-66.

Churbanova, I. Y. \& Sevrioukova, I. F. (2008). Redox-dependent changes in molecular properties of mitochondrial apoptosis-inducing factor. J Biol Chem 283, 5622-5631.

Collinson, E. J., Wheeler, G. L., Garrido, E. O., Avery, A. M., Avery, S. V. \& Grant, C. M. (2002). The yeast glutaredoxins are active as glutathione peroxidases. J Biol Chem 277, 16712-16717.

Du, L., Yu, Y., Chen, J., Liu, Y., Xia, Y., Chen, Q. \& Liu, X. (2007). Arsenic induces caspase- and mitochondria-mediated apopotosis in Saccharomyces cerevisiae. FEM Yeast Res 7, 860-865.
Dudgeon, D. D., Zhang, N., Ositelu, O. O., Kim, H. \& Cunningham, K. W. (2008). Nonapoptotic death of Saccharomyces cerevisiae cells that is stimulated by $\mathrm{Hsp} 90$ and inhibited by calcineurin and $\mathrm{Cmk} 2$ in response to endoplasmic reticulum stresses. Eukaryot Cell 7, 2037-2051.

Eckers, E., Bien, M., Stroobant, V., Herrmann, J. M. \& Deponte, M. (2009). Biochemical characterization of dithiol glutaredoxin 8 from Saccharomyces cerevisiae: the catalytic redox mechanism redux. Biochemistry 48, 1410-1423.

Garcerá, A., Barreto, L., Piedrafita, L., Tamarit, J. \& Herrero, E. (2006). Saccharomyces cerevisiae cells have three omega-class glutathione transferases acting as 1-Cys thiol transferases. Biochem J 398, 187-196.

Gari, E., Piedrafita, L., Aldea, M. \& Herrero, E. (1997). A set of vectors with a tetracycline-regulatable promoter system for modulated gene expression in Saccharomyces cerevisiae. Yeast 13, 837-848.

Gietz, R. D. \& Sugino, A. (1988). New yeast-Escherichia coli shuttle vectors constructed with in vitro mutagenized yeast genes lacking sixbase pair restriction sites. Gene 74, 527-534.

Gomes, D. S., Pereira, M. D., Panek, A. D., Andrade, L. R. \& Eleutherio, E. C. A. (2008). Apoptosis as a mechanism for removal of mutated cells of Saccharomyces cerevisiae: the role of Grx2 under cadmium exposure. Biochim Biophys Acta 1780, 160-166.

Hatfield, D. L., Berry, M. J. \& Gladyshev, V. N. (2006). Selenium: its Molecular Biology and Role in Human Health, 2nd edn. New York: Springer-Verlag.

Herrero, E. \& de la Torre-Ruiz, M. A. (2007). Monothiol glutaredoxins: a common domain for multiple functions. Cell Mol Life Sci 64, 1518-1530.

Herrero, E., Ros, J., Belli, G. \& Cabiscol, E. (2008). Redox control and oxidative stress in yeast cells. Biochim Biophys Acta 1780, 1217-1235. Izquierdo, A., Casas, C., Mühlenhoff, U., Lillig, C. H. \& Herrero, E. (2008). Yeast Grx6 and Grx7 are monothiol glutaredoxins associated with the early secretory pathway. Eukaryot Cell 7, 1415-1426.

Khan, M. A. S., Chock, P. B. \& Stadtman, E. R. (2005). Knockout of caspase-like gene, YCA1, abrogates apoptosis and elevates oxidized proteins in Saccharomyces cerevisiae. Proc Natl Acad Sci U S A 102, 17326-17331.

Letavayová, L., Vlckova, V. \& Brozmanová, J. (2006). Selenium: from cancer prevention to DNA damage. Toxicology 227, 1-14.

Letavayová, L., Vlasáková, D., Spallholz, J. E., Brozmanová, J. \& Chovanec, M. (2008). Toxicity and mutagenicity of selenium compounds in Saccharomyces cerevisiae. Mutat Res 638, 1-10.

Lewinska, A. \& Bartosz, G. (2008). A role for yeast glutaredoxin genes in selenite-mediated oxidative stress. Fungal Genet Biol 45, 11821187.

Li, W., Sun, L., Liang, Q., Wang, J., Mo, W. \& Zhou, B. (2006). Yeast AMID homologue Ndilp displays respiration-restricted apoptotic activity and is involved in chronological aging. Mol Biol Cell 17, 18021811.

Liang, Q. \& Zhou, B. (2007). Copper and manganese induce yeast apoptosis via different pathways. Mol Biol Cell 18, 4741-4749.

Lillig, C. H., Berndt, C. \& Holmgren, A. (2008). Glutaredoxin systems. Biochim Biophys Acta 1780, 1304-1317.

Lu, J. \& Holmgren, A. (2009). Selenoproteins. J Biol Chem 284, 723727.

Ludovico, P., Rodrigues, F., Almeida, A., Silva, M. T., Barrientos, A. \& Corte-Real, M. (2002). Cytochrome $c$ release and mitochondria involvement in programmed cell death induced by acetic acid in Saccharomyces cerevisiae. Mol Biol Cell 13, 2598-2606.

Luikenhuis, S., Perrone, G., Dawes, I. W. \& Grant, C. M. (1998). The yeast Saccharomyces cerevisiae contains two glutaredoxin genes that 
are required for protection against reactive oxygen species. Mol Biol Cell 9, 1081-1091.

Madeo, F., Fröhlich, E., Ligr, M., Grey, M., Sigrist, S. J., Wolf, D. H. \& Fröhlich, K. U. (1999). Oxygen stress: a regulator of apoptosis in yeast. J Cell Biol 145, 757-767.

Madeo, F., Herker, E., Maldener, C., Wissing, S., Lachelt, S., Herlan, M., Fehr, M., Lauber, K., Sigrist, S. J. \& other authors (2002). A caspaserelated protease regulates apoptosis in yeast. Mol Cell 9, 911-917.

Madeo, F., Herker, E., Wissing, S., Jungwirth, H., Eisenberg, T. \& Fröhlich, K. U. (2004). Apoptosis in yeast. Curr Opin Microbiol 7, 655-660.

Mániková, D., Vlasáková, D., Loduhová, J., Letavayová, L., Vigasová, D., Krascsenitsová, E., Vlcková, V., Brozmanová, J. \& Chovanec, M. (2010). Investigations on the role of base excision repair and nonhomologous end-joining pathways in sodium selenite-induced toxicity and mutagenicity in Saccharomyces cerevisiae. Mutagenesis 25, 155-162.

Marteyn, B., Domain, F., Legrain, P., Chauvat, F. \& Cassier-Chauvat, C. (2009). The thioredoxin reductase-glutaredoxins-ferroredoxin crossroad pathway for selenate tolerance in Synechocystis PCC6803. Mol Microbiol 71, 520-532.

Mazzoni, C. \& Falcone, C. (2008). Caspase-dependent apoptosis in yeast. Biochim Biophys Acta 1783, 1320-1327.

Mesecke, N., Mittler, S., Eckers, E., Herrmann, J. M. \& Deponte, M. (2008a). Two novel monothiol glutaredoxins from Saccharomyces cerevisiae provide further insight into iron-sulfur cluster binding, oligomerization, and enzymatic activity of glutaredoxins. Biochemistry 47, 1452-1463.

Mesecke, N., Spang, A., Deponte, M. \& Herrmann, J. M. (2008b). A novel group of glutaredoxins in the cis-Golgi critical for oxidative stress resistance. Mol Biol Cell 19, 2673-2680.

Miramar, M. D., Costantini, P., Ravagnan, L., Saraiva, L. M., Haouzi, D., Brothers, G., Penninger, J. M., Peleato, M. L., Kroemer, G. \& Susin, S. A. (2001). NADH oxidase activity of mitochondrial apoptosis-inducing factor. J Biol Chem 276, 16391-16398.

Modjtahedi, N., Giordanetto, F., Madeo, F. \& Kroemer, G. (2006). Apoptosis-inducing factor: vital and lethal. Trends Cell Biol 16, 264-272.

Molina, M. M., Bellí, G., de la Torre, M. A., Rodríguez-Manzaneque, M. T. \& Herrero, E. (2004). Nuclear monothiol glutaredoxins of Saccharomyces cerevisiae can function as mitochondrial glutaredoxins. J Biol Chem 279, 51923-51930.

Morton, C. O., Costa dos Santos, S. \& Coote, P. (2007). An amphibian-derived, cationic, $\alpha$-helical antimicrobial peptide kills yeast by caspase-independent but AIF-dependent programmed cell death. Mol Microbiol 65, 494-507.

Nargund, A. M., Avery, S. V. \& Houghton, J. E. (2008). Cadmium induces a heterogeneous and caspase-dependent response in Saccharomyces cerevisiae. Apoptosis 13, 811-821.

Pereira, C., Silva, R. D., Saraiva, L., Johansson, B., Sousa, M. J. \& Corte-Real, M. (2008). Mitochondria-dependent apoptosis in yeast. Biochim Biophys Acta 1783, 1286-1302.

Perrone, G. G., Tan, S. X. \& Dawes, I. W. (2008). Reactive oxygen species and yeast apoptosis. Biochim Biophys Acta 1783, 1354-1368.

Pinson, B., Sagot, I. \& Daignan-Fornier, B. (2000). Identification of genes affecting selenite toxicity and resistance in Saccharomyces cerevisiae. Mol Microbiol 36, 679-687.

Porras, P., Padilla, C. A., Krayl, M., Voos, W. \& Bárcena, J. A. (2006). One single in-frame AUG codon is responsible for a diversity of subcellular localizations of glutaredoxin 2 in Saccharomyces cerevisiae. J Biol Chem 281, 16551-16562.

Pozniakovsky, A. I., Knorre, D. A., Markova, O. V., Hyman, A. A., Skulachev, V. P. \& Severin, F. F. (2005). Role of mitochondria in the pheromone- and amiodarone-induced programmed death of yeast. J Cell Biol 168, 257-269.

Pujol-Carrión, N., Belli, G., Herrero, E., Nogués, A. \& de la TorreRuiz, M. A. (2006). Glutaredoxins Grx3 and Grx4 regulate the nuclear localization of Aft 1 and the oxidative stress response in Saccharomyces cerevisiae. J Cell Sci 119, 4554-4564.

Rodríguez-Manzaneque, M. T., Ros, J., Cabiscol, E., Sorribas, A. \& Herrero, E. (1999). Grx5 glutaredoxin plays a central role in protection against protein oxidative damage in Saccharomyces cerevisiae. Mol Cell Biol 19, 8180-8190.

Rodríguez-Manzaneque, M. T., Tamarit, J., Belli, G., Ros, J. \& Herrero, E. (2002). Grx5 is a mitochondrial glutaredoxin required for the activity of iron/sulfur enzymes. Mol Biol Cell 13, 1109-1121.

Salin, H., Fardeau, V., Piccini, E., Lelandais, G., Tanty, V., Lemoine, S., Jacq, C. \& Devaux, F. (2008). Structure and properties of transcriptional networks driving selenite stress response in yeasts. BMC Genomics 9, 333.

Seitomer, E., Balar, B., He, D., Copeland, P. R. \& Kinzy, T. G. (2008). Analysis of Saccharomyces cerevisiae null allele strains identifies a larger role for DNA damage versus oxidative stress pathways in growth inhibition by selenium. Mol Nutr Food Res 52, 1305-1315.

Sherman, F. (2002). Getting started with yeast. Methods Enzymol 350, 3-41.

Silva, R. D., Sotoca, R., Johansson, B., Ludovico, P., Sansonetty, F., Silva, M. T., Peinado, J. M. \& Corte-Real, M. (2005). Hyperosmotic stress induces metacaspase- and mitochondria-dependent apoptosis in Saccharomyces cerevisiae. Mol Microbiol 58, 824-834.

Spallholz, J. E. (1997). Free radical generation by selenium compounds and their prooxidant toxicity. Biomed Environ Sci 10, 260-270.

Susin, S. A., Lorenzo, H. K., Zamzami, N., Marzo, I., Snow, B. E., Brothers, G. M., Aebersold, R., Siderovski, D. P., Penninger, J. M. \& Kroemer, G. (1999). Molecular characterization of mitochondrial apoptosis-inducing factor. Nature 397, 441-446.

Tarze, A., Dauplais, M., Grigoras, I., Lazard, M., Ha-Duong, N. T., Barbier, F., Blanquet, S. \& Plateau, P. (2007). Extracellular production of hydrogen selenide accounts for thiol-assisted toxicity of selenite against Saccharomyces cerevisiae. J Biol Chem 282, 8759-8767.

Vahsen, N., Candé, C., Brière, J. J., Bénit, P., Joza, N., Larochette, N., Mastroberardino, P. G., Pequignot, M. O., Casares, N. \& other authors (2004). AIF deficiency compromises oxidative phosphorylation. EMBO J 23, 4679-4689.

Wach, A., Brachat, A., Pöhlmann, R. \& Philippsen, P. (1994). New heterologous modules for classical or PCR-based gene disruptions in Saccharomyces cerevisiae. Yeast 10, 1793-1808.

Weiner, M. P. \& Costa, G. L. (1995). Rapid PCR site-directed mutagenesis. In PCR Primer: a Laboratory Manual, pp. 613-621. Edited by C. W. Dieffenbach \& G. S. Dveksler. Cold Spring Harbor, NY: Cold Spring Harbor Laboratory.

Wissing, S., Ludovico, P., Herker, E., Büttner, S., Engelhardt, S. M., Decker, T., Link, A., Proksch, A., Rodrigues, F. \& other authors (2004). An AIF orthologue regulates apoptosis in yeast. J Cell Biol 166, 969-974.

Wu, M., Xu, L. G., Li, X., Zhai, Z. \& Shu, H. B. (2002). AMID, an apoptosisinducing factor-homologous mitochondrion-associated protein, induces caspase-independent apoptosis. J Biol Chem 277, 25617-25623.

Zhang, N. N., Dudgeon, D. D., Paliwal, S., Levchenko, A., Grote, E. \& Cunningham, K. W. (2006). Multiple signaling pathways regulate yeast cell death during the response to mating pheromones. Mol Biol Cell 17, 3409-3422.

Edited by: K. Kuchler 